\title{
Covid-19 and ex-smokers: an underestimated prognostic factor?
}

\author{
Pierluigi Carratù,, ${ }^{1}$ Roberto Boffi, ${ }^{2}$ Silvano Dragonieri, ${ }^{3}$ Elena Munarini, ${ }^{2}$ Chiara Veronese, ${ }^{2}$ \\ Piero Portincasa ${ }^{1}$ \\ ${ }^{1}$ Division of Internal Medicine, Clinica Medica “A. Murri”, Department of Biomedical Sciences and Human Oncology, \\ “Aldo Moro” University of Bari; ${ }^{2}$ SSD Pneumologia, Fondazione IRCCS Istituto Nazionale dei Tumori, Milano; \\ ${ }^{3}$ Institute of Respiratory Disease, Department of Basic Medical Science, Neuroscience and Sense Organs, "Aldo Moro" \\ University of Bari, Italy
}

Dear Editor,

The recent and explosive worldwide outbreak of Covid-19 leads many scientists and clinicians to identify the most responsible triggering risk factors in individuals without comorbidities, as well as potential prognostic factors [1].

A notable field of research has been conducted on the role of smoking, which has been initially hypothesized as being a protective factor for Covid-19 [2]. However, active cigarette smoking and Chronic Obstructive Pulmonary Disease (COPD) upregulate severe acute respiratory syndrome coronavirus 2 (SARS-CoV-2) receptor angiotensin-converting enzyme II (ACE-2) in the lower airways [3]. A very recent document published by the Italian Society of Tobaccology, analyzing 28 studies in which the smoking habit has been related to the development of this highly contagious disease, smoking subjects were more affected by Covid-19 than the non-smoking population [4]. Additionally, a previous Chinese study published on New England Journal of Medicine in February 2020 observed that, among 1.099 cases of Covid-19, $12,4 \%$ of smokers required admission to the Intensive Care or needed Invasive or non-Invasive Mechanical Assisted Ventilation, whereas only $4.7 \%$ of non-smokers necessitated the same intensive treatment [5].

Another underestimated aspect of Covid-19 pandemic is the high mean age ( 80 years) of casualties related to Covid-19 in Italy is similar to that of other countries. At least some of these patients could be previous smokers who may have stopped current smok-

Correspondence: Pierluigi Carratù, Division of Internal Medicine, Clinica Medica “A. Murri”, Department of Biomedical Sciences and Human Oncology, “Aldo Moro" University of Bari, Italy.

E-mail: pierluigi.carratu@uniba.it

Key words: Covid-19; smoking habit.

Received for publication: 19 June 2020.

Accepted for publication: 8 July 2020.

${ }^{\circ}$ Copyright: the Author(s), 2020

Licensee PAGEPress, Italy

Monaldi Archives for Chest Disease 2020; 90:1463

doi: 10.4081/monaldi.2020.1463

This article is distributed under the terms of the Creative Commons Attribution Noncommercial License (by-nc 4.0) which permits any noncommercial use, distribution, and reproduction in any medium, provided the original author(s) and source are credited. ing a variable number of years in the past. These patients may have been exposed to the pulmonary and extra-pulmonary damages of smoking for years.

In this respect, patients with COPD have worse outcomes from Covid-19 infection, since they often require mechanical ventilation, they have more chances of being admitted to an intensive care unit, and they have threefold odds ratio of dying [6]. In a recent paper, $\mathrm{Cai} \mathrm{H}$, et al. showed that a male predisposition might be associated with the much higher smoking rate of Covid-19 positive in men than in women in China (288 million men vs $12 \cdot 6$ million women) [7].

In conclusion, we suggest that when assessing the history of patients with COVID-19, previous exposure to smoking should be carefully investigated and properly analyzed, calculating the entire population affected by Covid-19. Thus, patients who were previous smokers should be grouped with active smokers, since their lungs have been similarly injured for years by the wellknown harmful effects of smoking.

\section{References}

1. Baj J, Karakuła-Juchnowicz H, Teresiński G et al. COVID-19: Specific and Non-Specific Clinical Manifestations and Symptoms: The Current State of Knowledge. J Clin Med 2020;9.

2. Lippi G, Henry BM. Active smoking is not associated with severity of coronavirus disease 2019 (COVID-19). Eur J Intern Med 2020;77:123-4.

3. Leung JM, Yang CX, Tam A et al. ACE-2 expression in the small airway epithelia of smokers and COPD patients: implications for COVID-19. Eur Respir J 2020;55.

4. Società Italiana di Tabaccologia. Fumare protegge dal Covid19? La SITAB dice NO. Comunicato stampa - 25 aprile 2020. https://www.tabaccologia.it/PDF/Comunicato\%20Stampa_SI TAB_Fumo $\% 20 \mathrm{e} \% 20$ Covid_25-04-2020.pdf

5. Guan WJ, Ni ZY, Hu Y, et al. Clinical Characteristics of Coronavirus Disease 2019 in China. N Engl J Med 2020:382:1708-20. doi: 10.1056/NEJMoa2002032.

6. Guan WJ, Liang WH, Zhao Y et al. Comorbidity and its impact on 1590 patients with COVID-19 in China: a nationwide analysis. Eur Respir J 2020;55.

7. Cai H. Sex Difference and Smoking Predisposition in Patients With COVID-19. Lancet Respir Med 2020;8:e20. doi: 10.1016/S2213-2600(20)30117-X 